\section{(6) OPEN ACCESS}

\title{
Medical performance and the 'inaccessible' experience of illness: an exploratory study
}

\author{
Emma Weitkamp, ${ }^{1}$ Alex Mermikides ${ }^{2}$
}

\begin{abstract}
${ }^{1}$ Science Communication Unit, The University of the West of England, Bristol, UK

${ }^{2}$ Department of Drama, Kingston University, KingstonUpon-Thames, Surrey UK
\end{abstract}

\section{Correspondence to} Dr Emma Weitkamp, Science Communication Unit, The University of the West of England, Frenchay Campus, Coldharbour Lane, Bristol BS16 1QY, UK; Emma.weitkamp@ uwe.ac.uk

Accepted 27 June 2016 Published Online First 26 July 2016

CrossMark

To cite: Weitkamp E, Mermikides A. Med Humanit 2016;42:186-193.

\section{ABSTRACT}

We report a survey of audience members' responses (147 questionnaires collected at seven performances) and 10 in-depth interviews (five former patients and two family members, three medical practitioners) to bloodlines, a medical performance exploring the experience of haematopoietic stem-cell transplant as treatment for acute leukaemia. Performances took place in 2014 and 2015. The article argues that performances that are created through interdisciplinary collaboration can convey otherwise 'inaccessible' illness experiences in ways that audience members with personal experience recognise as familiar, and find emotionally affecting. In particular such performances are adept at interweaving 'objectivist' (objective, medical) and 'subjectivist' (subjective, emotional) perspectives of the illness experience, and indeed, at challenging such distinctions. We suggest that reflecting familiar yet hard-to-articulate experiences may be beneficial for the ongoing emotional recovery of people who have survived serious disease, particularly in relation to the isolation that they experience during and as a consequence of their treatment.

\section{INTRODUCTION}

This article explores research (designed and implemented by Emma Weitkamp) that tested the capacity of one example of 'medical performance' (created through a project led by Alex Mermikides) to convey a particularly 'inaccessible' experience of illness and medical treatment to people with different prior knowledge of this subject matter. Medical performance will be introduced below as an emerging category of arts practice, which, in some of its formats, can make a distinctive contribution to cultural understandings of illness and to the ongoing emotional recovery of people who have survived serious disease. Moreover, we argue that medical performances that are created through interdisciplinary collaboration are particularly effective in conveying experiences of serious illness because of their capacity to challenge polarised distinctions between 'objective' medical knowledge and 'subjective' experience.

The value of the arts as a means of exploring and conveying subjective experiences of illness has long been recognised, most recently in Bates, Bleakely and Goodman's Medicine, Health and the Arts, ${ }^{1}$ an important positioning of the arts within the scope of the medical humanities. Bates et al's inclusion of performance within this volume is unusual and reflects a proliferation, and increased recognition, of performance practices that surround 'medical systems and bodies' and which engage with 'social and personal realities' that open up in relation to these-this is 'medical performance' as defined by cultural scholar Petra Kuppers. ${ }^{2}$ In our articulation of the term, medical performance includes but goes beyond conventional theatre productions with medical subject matter (eg, Margret Edsom's Wit (1995)), encompassing autobiographical performances of illness (the subject of this paper); those that incorporate medical practices into performance (most famously, Orlan's surgery performances); as well as the use of performance techniques within medical education (eg, the Performing Medicine project (http://www.clodensemble.com/ medicine.htm).

In discussing an example of 'medical performance', our research seeks to situate performance more prominently within the scholarship on arts in health ${ }^{3}$ and to provide a bridge to performance scholarship concerned with patient experiences and medical practices and sciences. ${ }^{5-8}$ The concerns of the project discussed in this article also draw upon scholarship on pathography as a practice that conceptualises illness experiences through the creation of narratives. Initiated in seminal studies by Frank ${ }^{9}$ and Charon ${ }^{10}$ this field remains relevant to discussions of patient experiences and the expression of these through various art forms ranging from the graphic novel ${ }^{11}$ to performance. ${ }^{12}$ Indeed, a recent chapter by performance scholar Brodzinski ${ }^{13}$ posits performance created by 'patient-performers' as a way of actualising Frank's emphasis on embodiment-stories 'told not just about the body but through it' $(2016$, p. 3) by literally putting the body of the patient centre stage. More broadly, this article pertains to the ongoing project to problematise what Nettleton summarises as the 'biomedical model' of illness, ${ }^{14}$ a project founded by Foucault's seminal study of 'the clinic', ${ }^{15}$ which has been taken up, in various ways, within cultural studies, ${ }^{16}$ sociology ${ }^{17} 18$ and anthropology. ${ }^{19}{ }^{20} \mathrm{~A}$ text that was particularly influential upon the medical performance explored in this paper is Jackie Stacey's Teratologies: a cultural study of cancer, ${ }^{21}$ which draws upon all these fields of scholarship in order to navigate personal, social and cultural meanings of this illness.

\section{BACKGROUND}

\section{An 'inaccessible' experience of illness}

Bloodlines seeks to convey a patient's experience of acute lymphoblastic leukaemia (ALL) and its treatment through haematopoietic stem-cell transplant (HSCT). ALL is a particularly aggressive cancer of the white blood cells with poor prognostic outcome in adults. In his biography of cancer, Murkharjee describes ALL as 'cancer in one of its most explosive, violent incarnations...terrifying to 
experience, terrifying to observe, and terrifying to treat'. ${ }^{22}$ For some patients the best chance of survival and possible cure is an HSCT. ${ }^{i}$ However, this treatment is only available to those for whom a compatible donor can be found and who are strong enough to withstand the preparatory regime, which is itself 'potentially lethal'. ${ }^{23}$ Nevertheless, since the mid-1990s HSCT has become a viable treatment option and research has focused on survival rates, and quality-of-life issues for transplant recipients and survivors. ${ }^{24}$

A study on the psychosocial experience of patients very recently diagnosed with acute leukaemia ${ }^{25}$ describes the 'existential crisis' of being suddenly faced with the immediate threat of death. This is exacerbated by immediate hospitalisation, the rush to undergo often invasive diagnostic tests (eg, bone marrow biopsies and lumbar punctures) and confrontation with unfamiliar medical terminology. A core category emerging from this study was 'uncertainty': why me? Will I survive?' A study of patients undergoing $\mathrm{HSCT}^{25}$ suggests that this uncertainty intensifies as therapy involves the constant evaluation and careful balancing of disease-related and treatment-related risks, with the threat of mortality ever present. A recent doctoral paper on the experience of HSCT summarises it as a 'severe disruption...in terms of their physical, psychosocial and emotional being and their everyday lives' (E Dunn. Safe in the Bubble, Out into the Unknown: returning home following allogeneic stem cell transplantation. $\mathrm{PhD}$ thesis submitted to University of Surrey, September 2014. http://epubs.surrey.ac.uk/808305/).

This study also foregrounds isolation as an important consideration, both because limits on visitors (to protect the patient during periods of immunosuppression) curtails the emotional support of family and friends, and in the sense of undergoing an experience that others do not understand. A particularly isolating aspect of this illness/treatment experience is that it seems to exceed established ways of conceptualising the body and mind. Transplant survivor and psychologist Ron Morstyn ${ }^{26}$ describes his own struggle to access and explain the experience, how it necessitated a profound shift in his sense of himself as an embodied being. This shift could not be encompassed by the perspectives that he encountered during his treatment: what he called 'objectivist' (exclusive focus on physical symptoms of the medical profession) nor 'subjectivist' (an equally inadequate exclusive focus on emotion and subjectivity) perspectives. The creators of bloodlines posited that a performance created through a process of interdisciplinary collaboration and a dramatic form that layered and interwove different perspectives and art forms would enable them to blend these perspectives and thereby capture at least some aspects of this illness experience.

\section{Bloodlines: blending 'objectivist' and 'subjectivist' perspectives}

Bloodlines is the product of a practical research project supported by the Arts and Humanities Research Council under the Science in Culture theme, led by Alex Mermikides, that explored devising as a methodology for creating medical performances. Devising is a form of performance-making that favours collaboration-in this case interdisciplinary collaboration-as a means of exploring diverse perspectives on a subject and creating alternative forms and narratives. ${ }^{27-29}$ The creative team of bloodlines represented a range of personal and disciplinary

${ }^{\mathrm{i}}$ Also known as bone marrow transplant although the two procedures differ in the harvesting process. perspectives, including a survivor of ALL (composer, Milton Mermikides), his sibling stem-cell donor (director, Alex Mermikides) and clinical haematologist (Ann Van de Velde). Also involved in the project were a choreographer, dancers and a digital artist specialising in science communication.

The performance that resulted from this collaboration includes two interwoven strands. One follows the experiences of a patient (performed by dancer/choreographer Adam Kirkham) through the treatment protocol for ALL with scenes on phases of chemotherapy, total body radiation that lead to a neutropenic state, and the transplant itself. The other is a series of medical lectures, performed initially by Ann Van de Velde, and in later performances, Dr Rebecca Law (a doctor-turned actor) on healthy and pathological blood formation, histocompatibility for transplant and the process of apheresis (harvesting of stem cells from the donor, performed by dancer Viv Rocha). The $30 \mathrm{~min}$ piece becomes increasingly abstract as treatment intensifies, the doctor's voice increasingly disembodied, and the two strands progressively more interwoven. Through this the 'medical' and the 'personal' perspectives are layered and blurred.

A key example of this 'blending' is a scene on histocompatibility for transplant. The scene opens with a snippet of lecture presented directly to the audience by the doctor, outlining the risks of transplant and the need for 'matched' donors. She is replaced by the patient, who then takes his place on a bed projected onto the back wall of the stage (see figure 1). A filmed image of the same dancer (wearing jeans rather than the characteristic jogging trousers of the patient) rolls onto the bed and there begins a duet between the live and filmed version of the patient, with a choreography involving a series of matched and mismatched postures and gestures. The quality of the movement is unadorned and repetitive, akin to movements one might enact during a medical examination and thereby suggestive, perhaps, of the patient's compliance with treatment. This dynamic is reinforced by the doctor's words, which now return as live voice-over, enumerating statistical probabilities of donorrecipient matches.

One reason that dance was a chosen form within this performance is its openness to interpretation. For example, the projected images of the patient in this scene might represent a series of would-be donors that are being assessed as potential matches; or the patient as his former healthy self and, with this, a hoped-for return to health; or as a hallucinated companion who might counter his loneliness. The range of potential meanings is contained to some degree by the doctor's text, yet individual audience members might attribute their own meanings to the scene and, for some, recognise aspects of their own experiences in it.

\section{Performances}

Bloodlines was performed in arts, academic, medical and science settings in the UK and Belgium, attracting audiences with a range of personal and professional relationships to the medical subject matter. Each performance included a postshow ' $Q \& A$ ' discussion with the creative team (sometimes with additional guests) and some were preceded by introductory talks by team members and/or invited specialist speakers. A summary of the performances discussed in this article is provided in table 1.

\section{AUDIENCE RESEARCH Research design}

Audience research was designed by Emma Weitkamp, who was not involved in the creation of bloodlines itself, but was invited 
Figure 1 Bloodlines performance photo by Anna Tanczos.

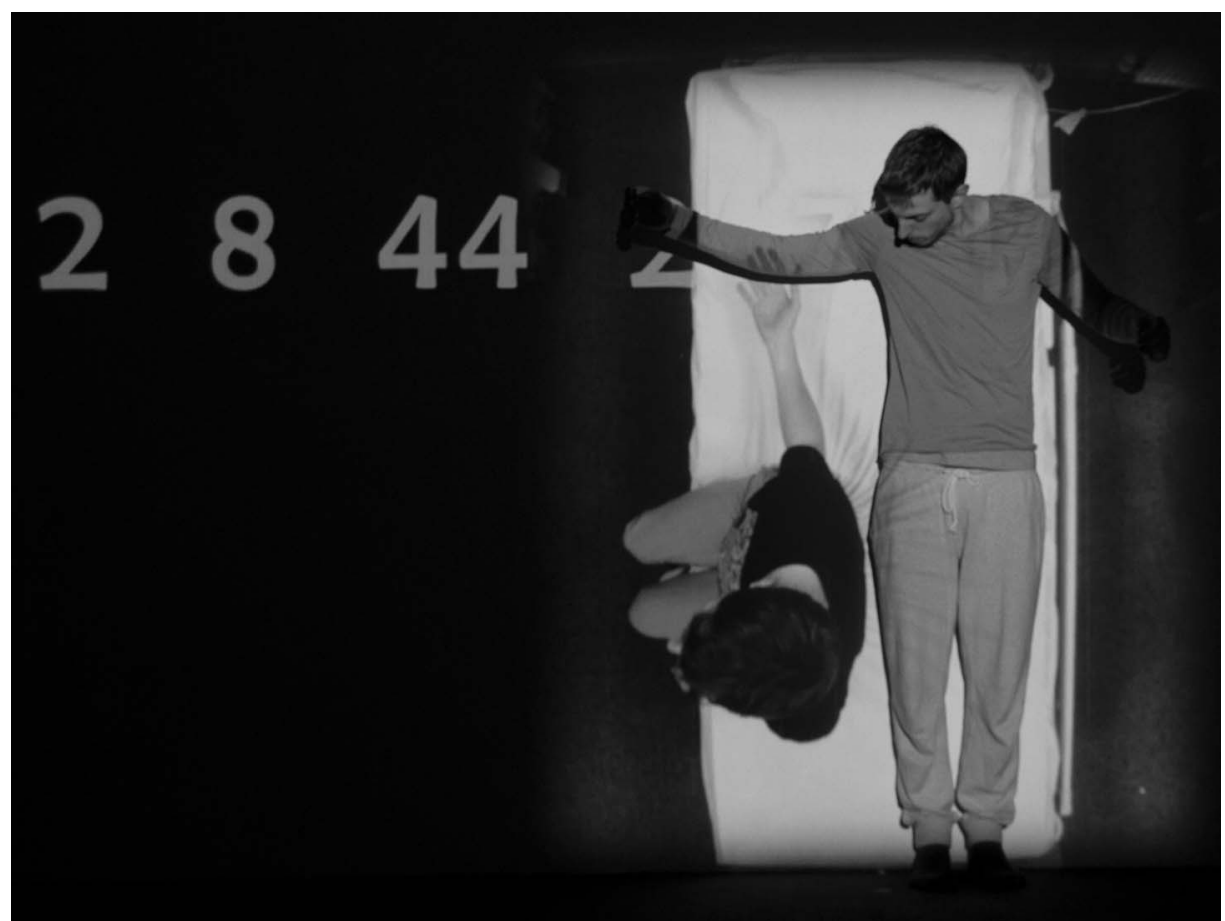

by the team after the performance had been devised to explore its impact on audiences. The research uses a mixed method design comprising two elements: a short questionnaire distributed to and completed by audience members immediately after the performance, and a series of in-depth semistructured interviews with select audience members that took place at least a week after the performance.

The survey element of the research design was developed through the creation of a postshow questionnaire that comprised primarily open questions. This self-administered questionnaire was designed to explore themes emerging that related to the communication of information about HSCT and the subjective experience of the patient. The survey was administered at a developmental performance of bloodlines held at the Dana Centre, Science Museum, London, UK. Responses to this questionnaire $(n=29)$, together with five interviews with members of the audience (including those with medical, personal and no prior experience of HSCT), were used to construct a range of questions to explore whether the performance communicates both the 'objectivist' and 'subjectivist' experience of HSCT. These were discussed within the performance development team (which comprised a range of experiences of HSCT) and revised to reflect their collective experience. The same approach was used to construct the questions used to categorise the audience member's experiences of HSCT. This yielded a pilot questionnaire comprising likert-like scale questions, which were always followed by an invitation to provide additional comments and one question inviting respondents to select three words that expressed their feelings about the performance (this question was useful for us to gauge responses to the performance at this early stage, but was not included in the final questionnaire as it did not address the aims of the survey directly and to enable a shorter questionnaire that could be handed to audience members as they left the performance). Twenty completed pilot questionnaires were analysed for clarity of question wording as well as to ensure that each question produced a spread of responses.
The final questionnaire comprised closed and open questions to gather data on audience background, and their perspectives on the performance. In terms of background, respondents were asked about their previous experience of HSCT: professional experience (eg, medical practitioner or affiliated to a registry), personal experience (eg, as a transplant recipient, donor or known to a recipient or donor) or as having no previous knowledge or experience (an option was also provided for those preferring not to reveal this information). Closed questions relating to the performance were designed to explore the balance between 'objectivist' and 'subjectivist' aspects, asking whether it communicated information about the subject matter and increased their understanding of HSCT, as well as exploring the extent to which it conveyed the subjective experience of the patient. Open questions invited the audience to elaborate on these views. The questionnaire also sought to explore general attitudes towards theatre as a means of communicating medical information. One hundred and forty-seven questionnaires were received from seven performances in a range of venues (see table 1). Questionnaire data were analysed using SPSS, V.22. Where cell sizes allowed, Pearson's chi-squared tests have been used to test statistical differences between audience members having professional, personal or no previous experience of HSCT.

A set of questionnaires collected from medical professionals attending the Belgian Haematological Society Conference (BHC) were subjected to additional analysis. As English is unlikely to be the first language of this audience, we explored whether those completing the questionnaire were more or less likely to provide open comments as one way to assess the impact of language. Participants from the BHC were slightly less likely to make open responses than other groups $(39 \% ; n=17$ BHC respondents made open comments, compared with $67 \%$ $(n=14)$ of people with personal experience and $47 \%(n=23)$ of people with no experience), suggesting that the language of the questionnaire might have reduced willingness to provide open comments (though this could equally be related to professional 
Table 1 Performance details

\begin{tabular}{|c|c|c|c|}
\hline Venue & Audience approx number/type & Accompanying events & Data collected \\
\hline Rose Theatre (2014), Kingston & 30/General* & Postshow discussion with creative team & Questionnaires: 20 \\
\hline $\begin{array}{l}\text { Royal Central School of Speech } \\
\text { and Drama (2014) }\end{array}$ & $80 /$ Performance researchers and students & Postshow discussion with creative team & Questionnaires: 16 \\
\hline $\begin{array}{l}\text { Antwerp University Hospital } \\
\text { (UZA; 2014) }\end{array}$ & $\begin{array}{l}\text { 180/Transplant survivors and their } \\
\text { families. Staff from UZA }\end{array}$ & $\begin{array}{l}\text { Introductions by UZA staff; presentations by two } \\
\text { transplant survivors }\end{array}$ & $\begin{array}{l}\text { Questionnaires were not } \\
\text { distributed }\end{array}$ \\
\hline $\begin{array}{l}\text { Event celebrating } 30 \text { years of } \\
\text { transplant at UZA }\end{array}$ & $\begin{array}{l}\text { Film of performance shown to } 20 \text { medical } \\
\text { staff unable to attend performance }\end{array}$ & $\begin{array}{l}\text { Introduction by Ann Van de Velde, postshow discussion } \\
\text { with Alex Mermikides (director) and Kirkham }\end{array}$ & $\begin{array}{l}\text { Interviews with five patients, } \\
\text { two partners, one nurse }\end{array}$ \\
\hline $\begin{array}{l}\text { Belgian Haematological Society } \\
\text { Conference (2015) }\end{array}$ & 200/Specialist nurses & $\begin{array}{l}\text { Part of conference programme. Introduction by } \\
\text { Ann Van de Velde. Postshow discussion with creative } \\
\text { team }\end{array}$ & Questionnaires: 44 \\
\hline $\begin{array}{l}\text { Ivy Centre (2015), Guildford } \\
\text { University of Surrey }\end{array}$ & 30/General & $\begin{array}{l}\text { Preshow talks by blood cancer nurse; theatre } \\
\text { professionals (director and composer) } \\
\text { Postshow discussion with creative team }\end{array}$ & $\begin{array}{l}\text { Questionnaires: } 18 \\
\text { Interviews with two healthcare } \\
\text { professionals }\end{array}$ \\
\hline $\begin{array}{l}\text { Rose Theatre (2015) Kingston } \\
\text { Connections Festival }\end{array}$ & 40/General & Postshow discussion with creative team & Questionnaires: 20 \\
\hline $\begin{array}{l}\text { Clapham Omnibus (2015) Inside } \\
\text { Out Festival }\end{array}$ & 20/General & $\begin{array}{l}\text { Postshow discussion with creative team and bone } \\
\text { marrow registry representative }\end{array}$ & Questionnaires: 4 \\
\hline $\begin{array}{l}\text { John Thaw Theatre (2015) } \\
\text { Manchester Science Festival }\end{array}$ & 40/General & $\begin{array}{l}\text { Preshow talks by director and composer } \\
\text { Postshow discussion with Cancer Research UK } \\
\text { representative and creative team }\end{array}$ & Questionnaires: 25 \\
\hline
\end{tabular}

role). However, it should be noted that the open comments received from this group were of similar length and covered similar topics/issues as those found in the other groups.

Qualitative data were collected via in-depth, semistructured interviews with patients (5), family members (2) and healthcare professionals (3) lasting from 15 to $45 \mathrm{~min}$. Interviews explored respondents' views on both the objective (medical) and subjective (experiential) content of the performance, the impact of the performance on the respondent (eg, in terms of how they think about their own personal or professional experience of transplant) and their views and experience of medical performance more generally. Interviews were carried out in English and it should be noted that English was not the first language of the eight interviewees who attended the performance at UZA. These interviewees were recruited via an email sent out to all audience members by Ann Van de Velde. They were informed in the email that the interviews would be conducted in English, and this is likely to have influenced the choice to participate, with only those more confident in English agreeing. During the interview process itself, care was taken to ensure that participants could clarify questions and have time to formulate their response. The interviewer also took time to clarify any answers that were unclear or ambiguous. While clearly these interviews were conducted in a second language, the individuals opting to participate spoke with ease during the interviews and did not seem to struggle to convey their ideas. Interviews were conducted by a research assistant or Emma Weitkamp via Skype or phone. None of these interviewees had previously attended a performance about a healthcare or medical issue, noting that they had not had the opportunity to do so before.

All interviews were first transcribed and then analysed thematically. ${ }^{30-32}$ This approach was chosen to enable the researchers to focus on key topics of relevance to the study, while generating rich data and allowing themes to emerge empirically from the data rather than being constrained through predetermined survey categories. Themes emerged during repeated reading of transcripts. Although Emma Weitkamp coded the interviews, preliminary codes and emerging themes were discussed and reflected on with Alex Mermikides to provide a wider perspective on the emerging findings and enhance the quality of the analysis. As Alex Mermikides has personal experience of HSCT, we felt that it was important that this in-depth knowledge was brought to the analysis and interpretation of the qualitative data. Any issues arising during analysis and coding (eg, in relation to interpretation of meaning) were discussed and agreed between the authors. The small number of interviews and exploratory nature of the study meant that immersing both authors in the interpretation of the data was more appropriate than sample coding followed by intercoder reliability checks. Findings reported here focus on emergent themes relating to reflection of interviewees' experiences (subjective and objective), responses to objectivist and subjectivist content of the performance, impact on the interviewee and potential influence on medical practice.

\section{Ethical considerations}

Ethical considerations associated with the performance itself relate to its autobiographical nature (which might lead to identification of former patients) and to the potential distress of audience members that may result from exposure to an emotive subject matter. The abstract nature of the performance ensured that no actual patients or medical professionals could be recognised. However, the patients upon whose experiences the performance was based (the director and the composer) were identifiable in publicity and through their participation in accompanying events. In both cases, the decision to forgo anonymity was made willingly by both parties. To mitigate against causing unacceptable levels of distress among audience members due to the emotive nature of the subject, the topic of the performance was clearly declared in advance publicity and attendance to the event was always voluntary (and in all but one case, free of charge). In the analysis below we mention one example of a transplant survivor who chose not to attend the performance because of the potential for emotional distress. For those who did attend, postshow discussions (which included participation by Milton Mermikides, himself a cancer and transplant 
Figure 2 The performance communicated the subjective experience of someone facing a serious disease and undergoing treatment.

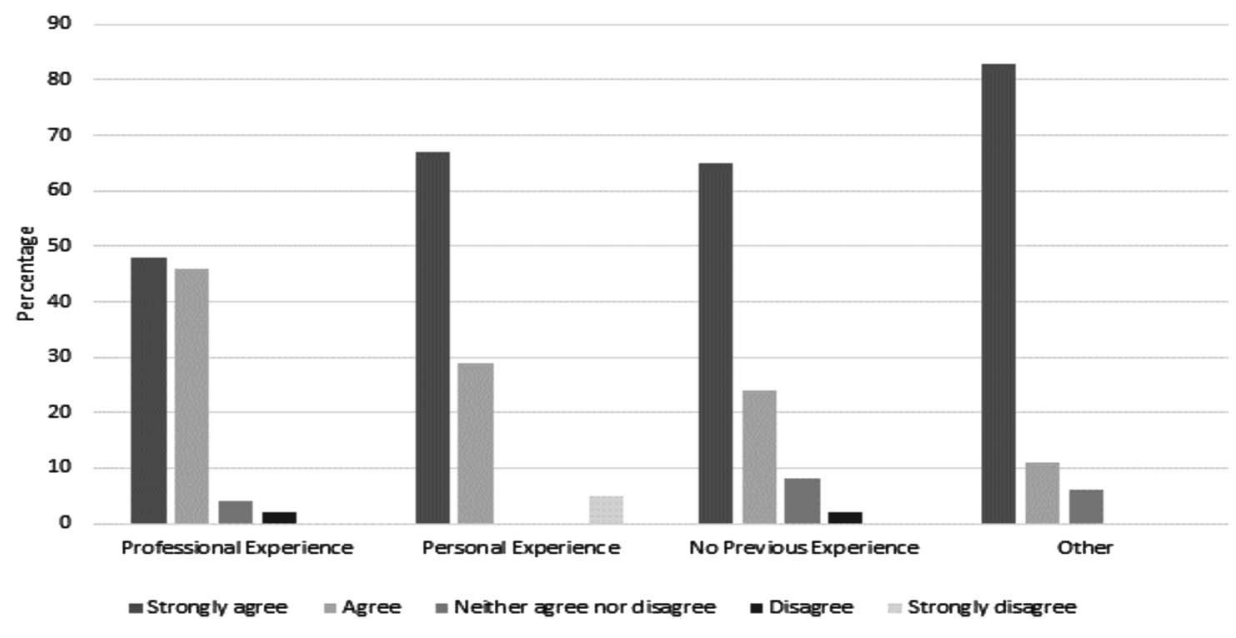

survivor) provided an opportunity to reflect on and express emotions provoked by the performance within a supportive context.

This same concern not to cause unnecessary levels of distress among audience members who might have negative personal experience relating to the subject matter was raised by the audience surveys. Participation in surveys was voluntary and those filling in questionnaires or consenting to participate in interviews were warned during consent-taking that they would be asked to declare personal experience of cancer and/or HSCT. Ethical approval for the research was provided by Kingston University Research Ethics Committee (1516CHA4).

\section{Audience characteristics}

The audience comprised 34\% $(n=50)$ healthcare professionals, $14 \%(n=21)$ with personal experience, $33 \%(n=49)$ with no previous experience of HSCT, 12\% $(n=18)$ indicated 'other' (which comprised a range of experience including studying biology at school or university) and $>1 \%(n=1)$ who preferred not to say (there were also eight missing responses). Thirty-eight percent $(n=56)$ had previously attended a performance about medical or scientific topics, while $59 \%(n=86)$ had not $(3 \%$, $\mathrm{n}=5$, missing responses). There was no statistical difference between audience groups (professional, personal, no experience or other) and whether they had previously attended a medical or scientifically themed performance $\left(\chi^{2} \quad(4, N=139)=4.1\right.$; $\mathrm{p}=0.35$ ), suggesting that the groups can be considered equally (un)familiar with the genre. As anticipated, venue did influence the backgrounds of the audience (one performance was given at the Belgian Haematological Society meeting, where $76 \%$ $(n=38)$ of respondents indicating professional experience were recruited). Three of the seven performances attracted no respondents with professional experience.

\section{Overview of responses}

Respondents overwhelmingly felt that the performance of bloodlines communicated information about stem-cell transplantation in an interesting and effective way (99\% strongly agree/agree, $n=145$; two people either disagreed or neither agreed nor disagreed) ${ }^{\mathrm{ii}}$ and that it conveyed the subjective experience of someone facing a serious disease or undergoing

${ }^{i i} \mathrm{Nb}$. the two people who did not agree with the statement also did not provide details of their past experience of HSCT, so are not included in figure 2. treatment $(93 \%, \mathrm{n}=136$ strongly agreed or agreed; 5\% neither agreed nor disagreed $(n=8)$ and $2 \%(n=3)$ disagreed or strongly disagreed). The overlap between these figures suggests that the performance was able to blend both the subjectivist and objectivist perspectives in a way that was relevant to the audience.

While all respondents who provided information about their past experience of HSCT agreed or strongly agreed with the statement 'the performance communicated information relating to stem cell transplant in an interesting and effective way', there was a statistically significant difference between groups $\left(\chi^{2}(3, n=138)=14.4 ; \mathrm{p}<0.005\right)$; those with personal experience or no previous knowledge were more likely to strongly agree with the statement. A similar trend is also apparent in relation to communication of the subjective experience of HSCT (figure 2).

Although more mixed, a large majority of the respondents also felt that the performance increased their understanding of the importance of matching a donor and a recipient of HSCT transplant $(82 \%, \mathrm{n}=120$ strongly agree/agree; $14 \%, \mathrm{n}=20$ neither agree nor disagree; and $3 \%, n=5$ strongly disagree/disagree). There is a trend for those with professional experience to indicate less agreement with the statement, which is not unexpected (and noted by some in the free text with comments such as 'only because I know it already', MSF25).

Respondents were asked to indicate their agreement (on a five-point Likert-like scale, $1=$ Strongly agree) with four statements about medical performances in general. Audience members strongly agreed that performance can make medical science relevant (median $=1.0$ ) and agreed that medical science should be portrayed accurately in such performances $($ median $=2.0)$. Audience members were neutral $($ median $=3$ ) about the importance of artistic quality and disagreed with the statement that 'engaging performance pieces rarely help the audience understand science/medical topics' (median=4). The data suggest a trend for those with no experience to be more likely to respond neutrally to the statement 'medical science should be portrayed accurately in performance pieces' (figure 3).

\section{TRANSPLANT SURVIVORS}

\section{Summary of comments}

All of the transplant patients interviewed (five) indicated that the performance reflected their own experience in many ways, particularly in relation to how they felt physically and emotionally as they went through diagnosis and treatment (and to an extent still feel). As interviewee 4 states "It captured how you 
Figure 3 Medical science should be portrayed accurately in performance pieces.

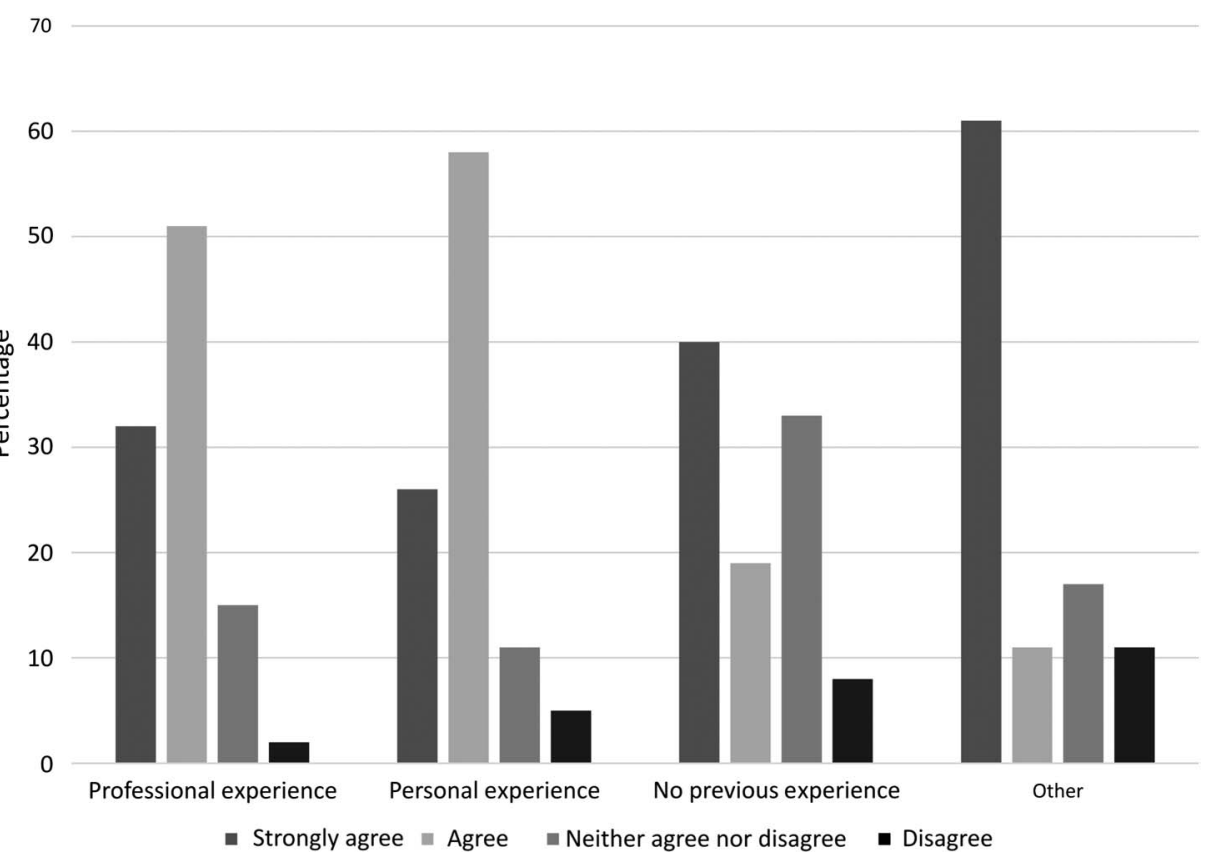

- Strongly agree = Agree $\quad$ Neither agree nor disagree - Disagree felt in that moment and it brought it back to life." This led to complex emotions for some audience members, who found that the performance brought back feelings they did not necessarily want to remember, though this was still perceived as a positive experience. As interviewee 2, who received his transplant just 11 months before seeing the show, explains: "A lot of feelings came back. Also a lot of feelings that I ... do not want to remember. But it was OK. It gave me lots of emotions inside.”

Responding to the final scene (a duet based on the posttransplant period when patients are at risk of a serious complication, graft-versus-host disease, in which donated cells attack those of the patient), one patient highlighted how the performance reflected physical processes: "The transplantation, the dance between the two bodies [...]. That was a true reflection of the battle between the new stem cells" (interviewee 5 who experienced graft-versus-host disease). Interviewee 7 pointed out that she had learned new medical information from the performance, which she did not remember hearing before, referring to the 'matching' scene described above: "I got information from the play, for example about the HLA types, which I didn't get from my own doctor." HLA (human leucocyte antigen) is the primary means used to match donors for transplantation.

Patient interviewees all commented that the performance conveyed the sense of the patient being alone, in hospital and going through a very traumatic experience. Interviewee 7 states: "for me, the message as a patient, was really that it's a hard time. It's very hard and you will be alone ... but afterwards it's all worth it." However, the performance also gave patients a sense that while they had been alone when going through treatment, others shared a similar experience and this was valued. As interviewee 5 explains: "There were many similarities [with my experience], processing the news, being alone, the fight to be alive, to believing. That's for me the feeling that bloodlines gave me-that I'm not alone with my situation." Performing to patients whose transplant had taken place at the same hospital provided an additional sense of 'togetherness'. As interviewee 2 notes "I didn't mind to remember all those things because it was being together with a lot of friends, although I didn't know the people.”
Most of the patients also mentioned that the performance highlighted for them how far they had come since their transplant. However, patients have to be ready to experience this type of event and to reflect on their experience in this way. Interviewee 6 notes about her husband, who was the transplant recipient, "he was not ill enough or cured enough to be open to an artistic evening." She goes on to suggest that this type of performance might be helpful to people before they have a transplant, as preparation so that "you can visualise what will happen in your body." A theme that was picked up by other interviewees, "it really gives an image of what you can expect-the bad things you have to go through first and then the good things to follow, but also, the warning for the risks that are concerned with [transplantation]."

Unprompted open comments on the questionnaire from those indicating personal experience of transplantation support these themes to an extent. For example, several respondents indicated learning something new, such as "I did not realise that donors could be unrelated-it was my understanding that it was not statistically viable for donors to be unrelated" (CSSD3) and "the $10^{23}$ revelation' (MSF2). Both of these comments refer to the challenge of finding a match with an unrelated donor (identified through registries such as the Anthony Nolan Trust or Delete Blood Cancer in the UK). The first comment is surprising given the efforts of these registries to advertise the need for potential donors to come forward for unrelated patients, though, as the 'revelation' suggests, the probability of a match in these cases is small.

Other open responses focused on the emotional engagement engendered by the performance such as "I found it very moving due to personal experience, and dealt with the emotions around diagnosis and treatment in an engaging and accurate and

\footnotetext{
iii Extracts of bloodlines have already been used in this context (eg, at the Patients Information Day at St. Georges Hospital in London) and informal responses in that context were positive. However, the creative team feel that some adaptations would need to be made before a full-length performance be employed in this way.
} 
emotive way" (Ivy4) and "the performance and information made me feel as well as think" (Ivy9).

\section{Benefits to transplant survivors and beyond}

The interview results suggest that the performance can provide a powerful cathartic experience for survivors of HSCT, for whom ongoing negative sequelae can include 'inability to resume social roles, sleep disturbance, infertility issues and physical and emotional distress [...] post-traumatic stress disorder and/or mood disorders, including anxiety and depression' (Beeken et al, p. 153). ${ }^{33}$ While watching a single performance is unlikely to address all these issues, the experience of reliving a negative experience within a safe and shared environment appears to have had a beneficial effect in terms of the emotional aspects, at least in the short term. The potential for longer-term benefits for transplant survivors is as yet untested, but one way in which the performance might bring these about is by encouraging patients to further reflect on their experiences with family members. As interviewee 4 explains,

“[...] it's often very hard to speak about that [experience of transplantation], about those emotions. So in that way, I can imagine that it can be a helpful tool to make a first step in talking about it. ... not all patients are open about their emotions when they go through such things."

Other interviewees explained how the performance would help family members understand what was happening to the patient, "I think that with this performance, the family of the patient will better understand how the medication changes the patient's behaviour" (interviewee 5).

Moreover, there are also indications that the capacity of the performance to convey the subjective experience of the patient may also be beneficial to professionals involved in their care. Three interviews were conducted with healthcare professionals in haematology (1) and other areas (2) to explore their views of the performance and its relevance to healthcare practice. The interviewees highlighted that the performance made them stop and think about their patients in new ways and encouraged them to reflect on their practice. Interviewee 8 (haematology nurse) felt that sometimes work got in the way of stopping to consider the patient as an individual rather than a medical case. As she explained, "some of them [doctors], I think, don't really see or feel or know what it is like [to be a patient]." Respondents to the questionnaire with healthcare backgrounds also highlighted this point "It helps us understand the patient's emotions" (BHC8). Interviewee 9 (orthopaedic nurse) was struck by the similarities between the performance and many of her patients who can become very attached to small medical details, like blood counts: "patients start to attach too much importance to insignificant changes. And I think it's very difficult to manage their responses to that." In a sense, her response was similar to the patients who felt less 'alone' when they shared the experience of watching the performance with other patients as she reported "it also made me think 'it's not just my patients'."

Additional comments from medical practitioners within postshow discussions or in informal conversations with members of the creative team draw attention to potential changes in medical practices that might benefit patients. For example, the postshow discussion at BHC included a lively conversation, prompted by an audience member's question on how nurses might support patients and families. This in turn provoked ideas such as subtle shifts in how medical procedures and therapies (which can be perceived as-and indeed are-invasive, toxic and threatening) are initially proposed to patients and improved internet ${ }^{34}$ and phone access for patients in isolation. The theme of isolation emerged repeatedly. For example, in the postshow discussion following a film screening of the performance for medical professionals at UZA, a senior clinician commented that, although having only one doctor in the performance was unrealistic, it added to his realisation of just how isolated patients are. Two nurses commented in an informal conversation following the performance at $\mathrm{BHC}$ that the performance had made them aware of how often patients are left alone and how distressing this might be, especially for child patients (eg, when undergoing radiotherapy). The capacity for the performance to encourage medical staff to reflect on their own patients and to look afresh at patient care suggests that the performance might contribute to medical and nurse education or continuing professional development, and indeed the bloodlines team have subsequently run workshops with trainee doctors and pathologists in major London teaching hospitals as part of the Performing Medicine project. Data from these and future activities, which will allow this aspect to be explored further.

\section{CONCLUDING REMARKS}

Medical performances such as bloodlines seem to offer a number of benefits for different audience groups. They can provide survivors of life-threatening illnesses with the opportunity to revisit and (re)conceptualise their traumatic experience. Through attending such performances, patients may develop a sense that they 'are not alone' in their experience, which might be heightened if the performance is attended with other patients (as was the case at UZA). The performance also seems to have the capacity to help those with no personal experience of transplantation to 'see or feel or know what it is like'. This may empower caregivers (family members as well as healthcare professionals) to better understand the experience and thereby empathise and support them through and beyond treatment. It might also encourage support of relevant charities by the general public.

A key factor enabling performance to bring about these benefits lies in its ability to capture illness/treatment experiences in a way that patients recognise, that feels familiar. This sense of familiarity may extend to medical professionals. For example, the cancer expert participating in the postshow discussion at MSF reported being struck by 'how familiar it feels, even though it's dance'. Indeed, an interesting observation is that the familiarity of the depicted experience tended to centre on scenes that are relatively abstract: the 'matching' scene described earlier, or one in which the experience of neutropenia (a particularly immunologically and emotionally vulnerable period) is explored through a solo dance to the sound of white noise and against a back-drop of static. One survivor at the UZA performance (now a support worker at the same hospital) described this scene to the director as 'this is exactly how that felt'. Thus, the question of 'accuracy', raised by our survey in relation to medical science, could usefully be extended to the subjective aspect. Indeed, our study highlights the value of performance forms that blend multiple disciplinary and personal experiences of a medical subject matter, which interweave and ultimately blur the 'objectivist' and 'subjectivist' perspectives in a way that can capture otherwise 'inaccessible' illness experiences: as one respondent suggested, that "made me feel as well as think" (Ivy9).

Twitter Follow Emma Weitkamp at @e_weitkamp

Contributors EW designed the study and research tools, analysed the results and co-wrote the paper. AM devised the bloodlines performance, managed ethical review and consent, collected data and co-wrote the paper. 
Funding Arts and Humanities Research Council (grant no AH/K003518/1). Competing interests None declared.

Ethics approval Kingston University Ethics Research Ethics Committee.

Provenance and peer review Not commissioned; externally peer reviewed.

Data sharing statement This paper reports the data from questionnaires and interviews. Questionnaire data are reported in full and a data set can be obtained from the corresponding author. Interview data have been analysed thematically and reported anonymously. These data are not currently available more widely as in some cases it might be possible to identify individuals from the original transcripts.

Open Access This is an Open Access article distributed in accordance with the Creative Commons Attribution Non Commercial (CC BY 4.0) license, which permits others to distribute, remix, adapt, build upon this work non-commercially, and license their derivative works on different terms, provided the original work is properly cited and the use is non-commercial. See: http://creativecommons.org/ licenses/by-nc/4.0/

\section{REFERENCES}

1 Bates V, Bleakley A, Goodman S. Medicine, health and the arts: approaches to the medical humanities. Oxon and New York: Routledge, 2014.

2 Kuppers P. The scar of visibility: medical performances and contemporary art. Minneapolis: University of Minnesota Press, 2007.

3 Warren B. Using the creative arts in therapy and healthcare: a practical introduction. Sussex and New York: Routledge, 2008.

4 Senior P, Croall J. Helping to heal: arts in healthcare. London: Calouste Gulbenkian 1993.

5 Brodzinski E. Theatre in health and care. Basingstoke: Palgrave MacMillan, 2010.

6 Bouchard G, O'Brien M. eds. On Medicine. Performance research, 2014:19:1-146. http://www.performance-research.org/past-issue-detail.php?issue_id=73.

7 Shepherd-Barr K. Science on stage: from Doctor Faustus to Copenhagen. Princeton: Princeton University Press, 2006.

8 Zehelein E. Science: Dramatic — Science Plays in America and Great Britain, 19902007. Heidelberg: Universitatverlag Winter, 2009.

9 Frank AW. The wounded storyteller: body, illness and ethics. Chicago and London: University of Chicago, 1995.

10 Charon R. Narrative medicine: honouring the stories of illness. Oxford: Oxford University Press, 2006.

11 Williams I. Graphic medicine: the portrayal of illness in underground and autobiographical conmis. In Bates V, Bleakley A, Goodman S, eds. Medicine, health and the arts: approaches to the medical humanities. Oxon and New York: Routledge, 2014:64-84.

12 Brodzinski E. Performance anxiety: the relationship between social and aesthetic drama in medicine and health. In Bates V, Bleakley A, Goodman S, eds. Medicine, health and the arts: approaches to the medical humanities. Oxon and New York: Routledge, 2014:165-85.

13 Brodzinski E. The patient performer: embodied pathography in contemporary productions. In Mermikides A, Bouchard G, eds. Performance and the medical body. London: Methuen Bloomsbury, 2016:85-98.

14 Nettleton S. The sociology of health and illness. Cambridge, Massachusetts: Polity Press, 1995, 2006, 2013.

15 Foucault M. The birth of the clinic. London and New York: Routledge, 2003 (first published in English by Tavistock Publication in 1973).

16 Sontag S. Illness as a metaphor \& aids and its metaphors. London: Penguin Book, 2002 (original publications in 1978 and 1989).

17 Barry A, Yuill C. Understanding the sociology of health. London: Sage, 2013.

18 White K. An Introduction to the sociology of health and illness. London: Sage, 2009.

19 Romonucci-Rose L, Moerman D, Tancredi L, eds. The anthropology of medicine: from culture to method. Connecticut: Sage, 2003.

20 Manderson L, Smith-Morris C, eds. Chronic conditions, fluid states: chronicity and the anthropology of illness. New Brunswick: Rutgers University Press, 2010.

21 Stacey J. Teratologies: a cultural study of cancer. London and New York: Routledge, 1997.

22 Mukherjee S. The emperor of all maladies: a biography of cancer. London: Fourth State, 2011:11.

23 Fielding $A$. Current treatment of Philadelphia positive acute lymphoblastic leukaemia. Haematologica 2010;95:8-12.

24 Hjermstad MJ, Kaasa S. Quality of life in adult cancer patients treated with bone marrow transplantation - a review of the literature. Eur J Cancer 1995;31A:163-73.

25 Koenigsmann $M$, Koehler $K$, Regner $A$, et al. Facing mortality: a qualitative in-depth interview study on illness perception, lay theories and coping strategies of adult patients with acute leukemia 1 week after diagnosis. Leuk Res 2006;30:1127-34.

26 Morstyn R. Merleau-Ponty and me: some phenomenological reflections upon my recent bone marrow transplant. Aust Psychiatry 2009;17:237-9.

27 Heddon D, Milling J. Devising performance: a critical history. Basingstoke: Palgrave, 2009.

28 Govan E, Nicholson H, Normington K. Making a performance: devising histories and contemporary practices. London: Routledge, 2007.

29 Dowell E, Weitkamp E. An exploration of the collaborative processes of making theatre inspired by science. Public Underst Sci 2012;21:891-901.

30 Mason J. Qualitative researching. London: Sage, 2002.

31 Dawson E, Hill A, Barlow J, et al. Genetic testing in a drama and discussion workshop: exploring knowledge construction. Res Drama Educ 2009;14:361-90.

32 Yardley L. Dilemmas in qualitative health research. Psychol Health 2012;15:215-28.

33 Beeken RJ, Eiser C, Dalley C. Health-related quality of life in haematopoietic stem cell transplant survivors: a qualitative study on the role of psychosocial variables and response shifts. Qual Life Res 2011;20:153-60.

34 The value of 'blogs' for patients with leukaemia is discussed in Nesby L, Salamonsen A. Youth blogging and serious illness. Med Humanit 2016;42:46-51. 